\title{
Transnasal endoscopy with narrow-band imaging and Lugol staining to screen patients with head and neck cancer whose condition limits oral intubation with standard endoscope (with video) $\square \checkmark$
}

\author{
Yi-Chia Lee, MD, Cheng-Ping Wang, MD, Chien-Chuan Chen, MD, Han-Mo Chiu, MD, Jenq-Yuh Ko, MD, PhD, \\ Pei-Jen Lou, MD, PhD, Tsung-Lin Yang, MD, Hsin-Yi Huang, MD, Ming-Shiang Wu, MD, PhD, \\ Jaw-Town Lin, MD, PhD, Tony Hsiu-Hsi Chen, PhD, Hsiu-Po Wang, MD
}

Taipei, Taiwan

Background: Early detection of esophageal cancer in patients with head and neck cancers may alter treatment planning and improve survival. However, standard endoscopic screening is not feasible for some patients with tumor-related airway compromise or postirradiation trismus.

Objective: To evaluate a novel, sequential approach by integrating ultrathin endoscopy with narrow-band imaging and Lugol chromoendoscopy.

Design: Cross-sectional study.

Setting: Single center in Taiwan.

Patients: Forty-four consecutive patients with transoral difficulty screened for synchronous or metachronous esophageal cancer.

Main Outcome Measurements: Sensitivity, specificity, and accuracy in the detection of mucosal high-grade neoplasia or invasive cancer.

Results: Fifty-four endoscopic interpretations were obtained, and 11 mucosal high-grade neoplasia and 7 invasive cancers were confirmed by histology. The mean examination time was 19.4 minutes (range 7.9-35.2 minutes), and all patients tolerated the procedure well. Sensitivity, specificity, and accuracy (with 95\% CI) were 55.6\% (95\% CI, 33.5\%-75.6\%), 97.2\% (95\% CI, 85.8\%-99.3\%), and 83.3\% (95\% CI, 71.2\%-90.9\%), respectively, for standard endoscopy; 88.9\% (95\% CI, 66.9\%-96.6\%), 97.2\% (95\% CI, 85.8\%-99.3\%), and 94.4\% (95\% CI, 84.9\%-97.9\%), respectively, with the adjunct of narrow-band imaging; and 88.9\% (95\% CI, 66.9\%-96.6\%), 72.2\% (95\% CI, 55.9\%-84.1\%), and 77.8\% (95\% CI, 64.9\%-86.8\%), respectively, with the adjunct of Lugol chromoendoscopy. When we integrated all interpretations on the basis of the sequential approach, the estimated probability of false-negative findings was $1.2 \%$ (95\% CI, 0.1\%-4.6\%).

Limitations: Inherent shortcomings of ultrathin endoscopy, such as its resolution, light source, and lack of magnification.

Conclusions: The use of ultrathin endoscopy in a sequential approach for multimodal detection is feasible in patients with transoral difficulty and substantially increases the detection rate of synchronous or metachronous neoplasms. (Gastrointest Endosc 2009;69:408-17.)

Abbreviations: H pylori, Helicobacter pylori; LVL, Lugol-voiding lesion; $N B I$, narrow-band imaging; NPV, negative-predictive value; PPV, positive-predictive value.

DISCLOSURE: All authors disclosed no financial relationships relevant to this publication. Olympus Medical Systems Corp, Tokyo, Japan, provided the NBI system.

Copyright $\odot 2009$ by the American Society for Gastrointestinal Endoscopy 0016-5107/\$36.00

doi:10.1016/j.gie.2008.05.033
Squamous-cell carcinoma of the aerodigestive tract is related to the use of tobacco and alcohol, as well as to chewing of betel nuts, which is prevalent in many developing countries. ${ }^{1,2}$ Despite a multidisciplinary approach, which includes surgery, radiotherapy, and chemotherapy alone or in combination, the survival rate of patients with this type of carcinoma remains unsatisfactory. ${ }^{3,4}$ 
The concept of field carcinogenesis suggests that esophageal cancer may appear as synchronous or metachronous tumors in approximately $14.2 \%$ of patients with head and neck cancers. ${ }^{5-9}$ This occurrence may account for the poor prognosis, despite adequate control of the primary tumor.

Advanced endoscopic techniques, such as Lugol chromoendoscopy and high-resolution magnifying endoscopy, enable early detection of esophageal cancer. ${ }^{10-17}$ Curative endoscopic resection, therefore, is possible when the lesions are limited to the mucosa and are not metastatic. ${ }^{18,19}$ However, in some patients, tumor-related airway compromise or postirradiation trismus makes the oropharyngeal passages difficult to reach with conventional endoscopes. In addition, numerous areas tend not to stain with Lugol solution, and the choice to perform biopsy is highly operator dependent. ${ }^{19,20}$ Therefore, it is worthwhile to develop an alternative method to screen such patients by using small-caliber instruments without sacrificing the detection rate.

Carcinogenesis involves a dynamic process of tumoral vascularization in which dilated, elongated, or irregular tumoral vessels replace normal capillaries. ${ }^{21}$ Recent advances in narrow-band imaging (NBI) permit clinicians to adjust reflected light, enhance the vascular pattern, and increase detection of early stage mucosal malignancies $^{22-25}$ and minute inflammatory changes. ${ }^{26,27}$ By taking advantage of this technology, we evaluated the effectiveness of transnasal ultrathin endoscopy for screening high-risk patients with limited endoscopic assess. We assumed that the integration of standard endoscopy, NBI, and Lugol chromoendoscopy in a single session was achievable and that it would increase the detection rate. Testing this hypothesis was the main goal of our study. A secondary priority was to evaluate the screening performance of various combinations of these detection modalities.

\section{PATIENTS AND METHODS}

\section{Patients and design}

We prospectively recruited adults at high risk for esophageal cancers. They included patients with primary hypopharyngeal cancer who were referred for evaluation of synchronous lesions and patients who had completed treatment for previous head and neck cancer and who were referred for evaluation of metachronous lesions. Exclusion criteria were an allergy to iodine, previous esophageal resection, and/or total obstruction caused by the hypopharyngeal cancer. In all patients, navigation via the transoral route with a conventional endoscope was considered difficult because of tumor-related airway compromise or trismus after radiotherapy. Participants provided written informed consent, and the ethics committee of

\section{Capsule Summary}

\section{What is already known on this topic}

- Standard endoscopic screening for synchronous or metachronous esophageal cancer is not feasible in cases of tumor-related airway compromise or postirradiation trismus.

\section{What this study adds to our knowledge}

- In 44 consecutive patients who had difficulty with transoral screening for esophageal cancer and who were evaluated in a sequential manner, rates of sensitivity, specificity, and accuracy were $55.6 \%, 97.2 \%$, and $83.3 \%$, respectively, for standard endoscopy; $88.9 \%, 97.2 \%$, and $94.4 \%$, respectively, with the addition of narrow-band imaging; and $88.9 \%, 72.2 \%$, and $77.8 \%$, respectively, with the addition of Lugol chromoendoscopy.

the National Taiwan University Hospital approved the study protocol before its implementation.

\section{Transnasal ultrathin endoscopy}

After an overnight fast, the patients received topical anesthesia with cotton pledgets soaked in a mixture of cocaine and epinephrine, which were placed in their nasal cavities for 10 minutes. Two puffs of 10\% lidocaine (AstraZeneca, Södertälje, Sweden) were sprayed over the pharyngeal mucosa. Then, the patients were placed in the left lateral decubitus position for endoscopy. An ultrathin endoscope (GIF-XP260N; Olympus Optical Co, Ltd, Tokyo, Japan) was transnasally inserted. The endoscope was $5 \mathrm{~mm}$ in diameter at its distal end and had a 5.5- $\mathrm{mm}$ insertion tube and a 2-mm suction channel. Endoscopic biopsy was performed by using a small-caliber biopsy forceps with a 5-mm jaw opening (FB-19K-1; Olympus). An experienced endoscopist (Y.-C.L.) performed all examinations. The patients were not sedated, because of the high risk of airway compromise.

In a single session, all subjects underwent standard endoscopy, NBI, and Lugol chromoendoscopy, in this order. The endoscope was operated in a to-and-fro manner, and each examination was performed at least once to increase the detection rate. The stomach and duodenum were inspected, in addition to the esophagus, and the presence of Helicobacter pylori infection was determined by histology. Both static photographs and video clips were taken.

\section{NBI}

NBI is a new illumination method for endoscopy based on narrowing the spectral bandwidth of filtered light. Gono et $\mathrm{al}^{22}$ described this technique. We used the Evis Lucera Spectrum video imaging system for NBI (Olympus). ${ }^{26}$ After performing a standard endoscopy, the endoscopist switched the standard filter to the NBI filter by using a control knob on the grip of the endoscope. The 
neoplastic lesion was defined as an area that appeared brownish under NBI and was equated to the area of microvascular proliferation in the lesion. ${ }^{22-25}$ The locations of suspected lesions that were detected during standard endoscopy and NBI were recorded as their distance from the patient's nostrils.

\section{Lugol chromoendoscopy}

After NBI endoscopy, the endoscopist returned to the standard endoscope. He inserted a washing pipe that was $2 \mathrm{~mm}$ in outer diameter (PW-6P-1; Olympus) and sprayed 20 to $30 \mathrm{~mL}$ of $3 \%$ Lugol solution uniformly over the esophageal mucosa. A Lugol-voiding lesion (LVL) was defined as a well-demarcated, unstained area or a glycogen-depleted area with a diameter of $5 \mathrm{~mm}$ or greater (as determined by using an open biopsy forceps as a guide),${ }^{12,16}$ and LVLs were considered neoplastic. ${ }^{17}$

\section{Histology}

Biopsy samples of all endoscopically suspected lesions were obtained for histologic evaluation by a senior pathologist (H.-Y.H.). Because patients with high-grade neoplasia are candidates for endoscopic or surgical resection and because submucosal invasion increases the risk of nodal metastasis by about 35\%, ${ }^{1}$ we considered mucosal highgrade neoplasia and invasive cancer as index lesions. ${ }^{28}$ Carcinoma in situ and high-grade dysplasia were considered mucosal high-grade neoplasms. These lesions were characterized by disorganized epithelium, loss of normal cellular polarity, irregular and hyperchromatic nuclei, an increased nuclear-cytoplasmic ratio, and increased mitotic activity; all were confined to the mucosa. Invasion of the submucosa indicated invasive cancer.

\section{Statistical analysis}

Our primary outcome measures were the feasibility of performing the 3 endoscopic methods in a single session and their rates of detection. The results are presented as mean (SD) for continuous variables and as percentages for categorical variables. By using histologic findings as the criterion standard, we calculated the sensitivity, specificity, positive predictive value (PPV), negative predictive value (NPV), and accuracy for standard endoscopy, standard endoscopy with NBI, and standard endoscopy with Lugol chromoendoscopy. ${ }^{29}$ Statistical differences were compared by applying the $t$ test or $\chi^{2}$ test when appropriate. $P<.05$ indicated statistical significance. Statistical analyses were conducted by using a statistical software package (SAS version 9.1; SAS Institute Inc, Cary, NC).

Because we did not use specimens from surgically resected tumor as the criterion standard, false-negative results might have occurred even after sequential screening. We estimated the expected false-negative rate of interpretation by using a Monte Carlo computer simulation of data-set replications for 1000 neoplasms. In this simulation, results from NBI-based screening were assumed to be indepen-
TABLE 1. Demographic and endoscopic characteristics

\begin{tabular}{|c|c|}
\hline Demographic characteristics & $\begin{array}{l}\text { Patients } \\
(\mathrm{n}=44)\end{array}$ \\
\hline Mean (SD) age $(y)$ & $\begin{array}{l}60.5 \pm 11.4 \\
\text { (range 37-84) }\end{array}$ \\
\hline Male (no. [\%]) & $40(90.9)$ \\
\hline H pylori infection (no. [\%]) & $22(50)$ \\
\hline Smoking (no. [\%]) & $37(84.1)$ \\
\hline Alcohol (no. [\%]) & $32(72.7)$ \\
\hline Betel-nut chewing (no. [\%]) & $23(52.3)$ \\
\hline Peptic ulcer disease (no. [\%]) & $21(47.7)$ \\
\hline Erosive esophagitis (no. [\%]) & $11(25)$ \\
\hline $\begin{array}{l}\text { Patients with multiple Lugol unstained } \\
\text { areas }(>10)(\text { no. }[\%])\end{array}$ & $15(34.1)$ \\
\hline \multicolumn{2}{|l|}{ Reason for screening (no. [\%]) } \\
\hline Primary hypopharyngeal cancer & $22(50)$ \\
\hline Prior head and neck cancer & $22(50)$ \\
\hline \multicolumn{2}{|l|}{ Final diagnosis (no. [\%]) } \\
\hline Synchronous neoplasia & 8/22, (36.4) \\
\hline Metachronous neoplasia & $3 / 22,(13.6)$ \\
\hline \multicolumn{2}{|l|}{ Endoscopic characteristics } \\
\hline Endoscopically suspected neoplasia & $30(20 / 44)(45.5 \%)^{*}$ \\
\hline \multicolumn{2}{|l|}{ Histologic diagnosis (no. [\%]) } \\
\hline Minimal mucosal change & $5(16.7)$ \\
\hline Inflammation & $1(3.3)$ \\
\hline Squamous hyperplasia & $6(20)$ \\
\hline Mucosal high-grade neoplasia (no. [\%]) & $11(36.7)$ \\
\hline Invasive cancer (no. [\%]) & $7(23.3)$ \\
\hline
\end{tabular}

*Thirty lesions were detected in 20 patients.

dent of subsequent interpretations of Lugol chromoendoscopic images. ${ }^{30}$ The reason was that endoscopic morphologies substantially differed between these detection modalities. Derived CIs indicated the range of values likely to reflect true screening performance.

\section{RESULTS}

\section{Demographic characteristics}

Forty-six consecutive patients fulfilled the study criteria. Two were excluded from analysis owing to complete obstruction by hypopharyngeal tumors. The demographic characteristics of the remaining 44 patients ( 40 men [90.9\%]) are shown in Table 1. Twenty-two patients (50\%) had been referred for confirmatory diagnosis of 
TABLE 2. Screening performance and the corresponding $95 \%$ Cls of standard endoscopy, with and without the adjuncts of NBI or Lugol chromoendoscopy

\begin{tabular}{|c|c|c|c|c|c|}
\hline Modalities & $\begin{array}{c}\% \text { Sensitivity } \\
(95 \% \mathrm{CI})\end{array}$ & $\begin{array}{c}\% \text { Specificity } \\
(95 \% \mathrm{Cl})\end{array}$ & $\begin{array}{l}\% \text { PPV } \\
(95 \% \mathrm{CI})\end{array}$ & $\begin{array}{l}\% \text { NPV } \\
(95 \% \mathrm{Cl})\end{array}$ & $\begin{array}{c}\% \text { Accuracy } \\
(95 \% \mathrm{CI})\end{array}$ \\
\hline Standard endoscopy & $55.6(33.5-75.6)$ & $97.2(85.8-99.3)$ & $90.9(61.5-97.9)$ & $81.4(67.3-90.2)$ & $83.3(71.2-90.9)$ \\
\hline Standard endoscopy $+\mathrm{NBI}$ & $88.9(66.9-96.6)$ & $97.2(85.8-99.3)$ & $94.1(72.7-98.6)$ & $94.6(82.3-98.3)$ & 94.4 (84.9-97.9) \\
\hline $\begin{array}{l}\text { Standard endoscopy }+ \text { Lugol } \\
\text { chromoendoscopy }\end{array}$ & 88.9 (66.9-96.6) & $72.2(55.9-84.1)$ & $61.5(42.4-77.6)$ & $92.9(77.2-97.8)$ & $77.8(64.9-86.8)$ \\
\hline
\end{tabular}

hypopharyngeal tumors, as well as for screening of synchronous esophageal lesions. Another 22 with previous head and neck cancer underwent endoscopic screening because of new difficulties or pain on swallowing. Tobacco smoking (84.1\%), alcohol consumption (72.7\%), and betel-nut chewing (52.3\%) were prevalent behaviors; only 2 patients did not use these substances. Concomitant peptic ulcer disease was found in 21 (47.7\%) and erosive esophagitis in 11 (25\%). The prevalence of $H$ pylori infection was 50\%.

\section{Procedural characteristics}

The mean duration of endoscopy, including biopsy of hypopharyngeal lesions, was 19.4 minutes (range 7.935.2 minutes). Procedural time was longer for patients with primary hypopharyngeal cancer than for patients with previous head and neck cancer (22 vs 16.8 minutes; $P<.01)$. None of the patients developed an allergic reaction to iodine, and no complications occurred during or after the examinations.

During endoscopy, 30 suspicious lesions were found in 20 of 44 patients (45.5\%), and 18 of these lesions (60\%) were subsequently confirmed to be neoplasms. On average, esophageal lesions were $35.6 \mathrm{~cm}$ from the nostrils (range 22$45 \mathrm{~cm}$ ). When examining the integrity of the epithelial basement membrane, we dichotomized 11 high-grade mucosal neoplasms and 7 invasive squamous-cell carcinomas. The mean number of forceps biopsy specimens was 7.5 (range 2-18) and rose in patients with primary hypopharyngeal cancer versus those without primary hypopharyngeal cancer (8.9 vs $6.1 ; P<.01$ ). Overall, synchronous esophageal neoplasia was diagnosed in 8 of 22 patients (36.4\%) with hypopharyngeal cancer, and metachronous neoplasia was confirmed in 3 of 22 patients (13.6\%) with previous head and neck cancer. The prevalence of a second primary esophageal malignancy was highest in patients with untreated hypopharyngeal cancer $\left(\chi_{[1]}^{2}=3.03 ; P=.08\right)$. Multiple esophageal cancers were diagnosed in 5 patients (11.4\%), 3 with double neoplasms and 2 with triple neoplasms.

\section{Screening performance of standard endoscopy, NBI, and Lugol chromoendoscopy}

We interpreted findings from 54 endoscopic sessions to evaluate the screening performance of standard endoscopy, NBI, and Lugol chromoendoscopy. The sessions
TABLE 3. Detection rates by standard endoscopy, NBI, and Lugol chromoendoscopy in the 44 patients

\begin{tabular}{lccc} 
& $\begin{array}{c}\text { Standard } \\
\text { endoscopy, } \\
\mathbf{n}(\%)\end{array}$ & $\begin{array}{c}\text { NBI, } \\
\mathbf{n}(\%)\end{array}$ & $\begin{array}{c}\text { Lugol } \\
\text { chromoendoscopy, } \\
\mathbf{n}(\%)\end{array}$ \\
\hline $\begin{array}{l}\text { Negative for } \\
\text { neoplasia } \\
\text { (n = 36) }\end{array}$ & $1(2.8)$ & $1(2.8)$ & $10(27.8)$ \\
$\begin{array}{l}\text { Mucosal high- } \\
\text { grade neoplasia } \\
\text { (n = 11) }\end{array}$ & $3(27.3)$ & $9(81.8)$ & $9(81.8)$ \\
$\begin{array}{l}\text { Invasive cancer } \\
\text { (n = 7) }\end{array}$ & $7(100)$ & $7(100)$ & $7(100)$ \\
$\begin{array}{l}\text { All neoplasia } \\
\text { (n = 18) }\end{array}$ & $10(55.6)$ & $16(88.9)$ & $16(88.9)$ \\
\end{tabular}

led to 36 true-negative and 18 true-positive results. The sensitivity, specificity, PPV, NPV, and accuracy were 55.6\%, $97.2 \%, 90.9 \%, 81.4 \%$, and $83.3 \%$, respectively, for standard endoscopy; $88.9 \%, 97.2 \%, 94.1 \%, 94.6 \%$, and $94.4 \%$, respectively, for NBI endoscopy; and 88.9\%, 72.2\%, 61.5\%, $92.9 \%$, and $77.8 \%$, respectively, for Lugol chromoendoscopy (Table 2). The sensitivity of both NBI and Lugol chromoendoscopy (88.9\%) was better than that of standard endoscopy alone $\left(55.6 \% ; \chi_{[1]}^{2}=4.98 ; P=.03\right.$ ). The specificity of both standard endoscopy and NBI (97.2\%) was higher than that of Lugol chromoendoscopy (72.2\%; $\left.\chi_{[1]}^{2}=8.69, P<.01\right)$. The PPV of NBI was significantly better than that of Lugol chromoendoscopy (94.1\% vs $61.5 \% ; \chi_{[1]}^{2}=5.73 ; P=.02$ ). The accuracies or NPVs of these 2 methods were not significantly different.

\section{Interpretation based on integration of standard endoscopy with NBI or Lugol chromoendoscopy}

The detection rates for the techniques are shown in Table 3. Perfect concordance was noted in the detection of 7 invasive cancers. For the high-grade mucosal lesions, only 3 (27.3\%) were detected with standard endoscopy. Seven of 11 high-grade mucosal lesions were identified with both NBI and Lugol chromoendoscopy (Fig. 1); the remaining 4 lesions were identified with one of the two 

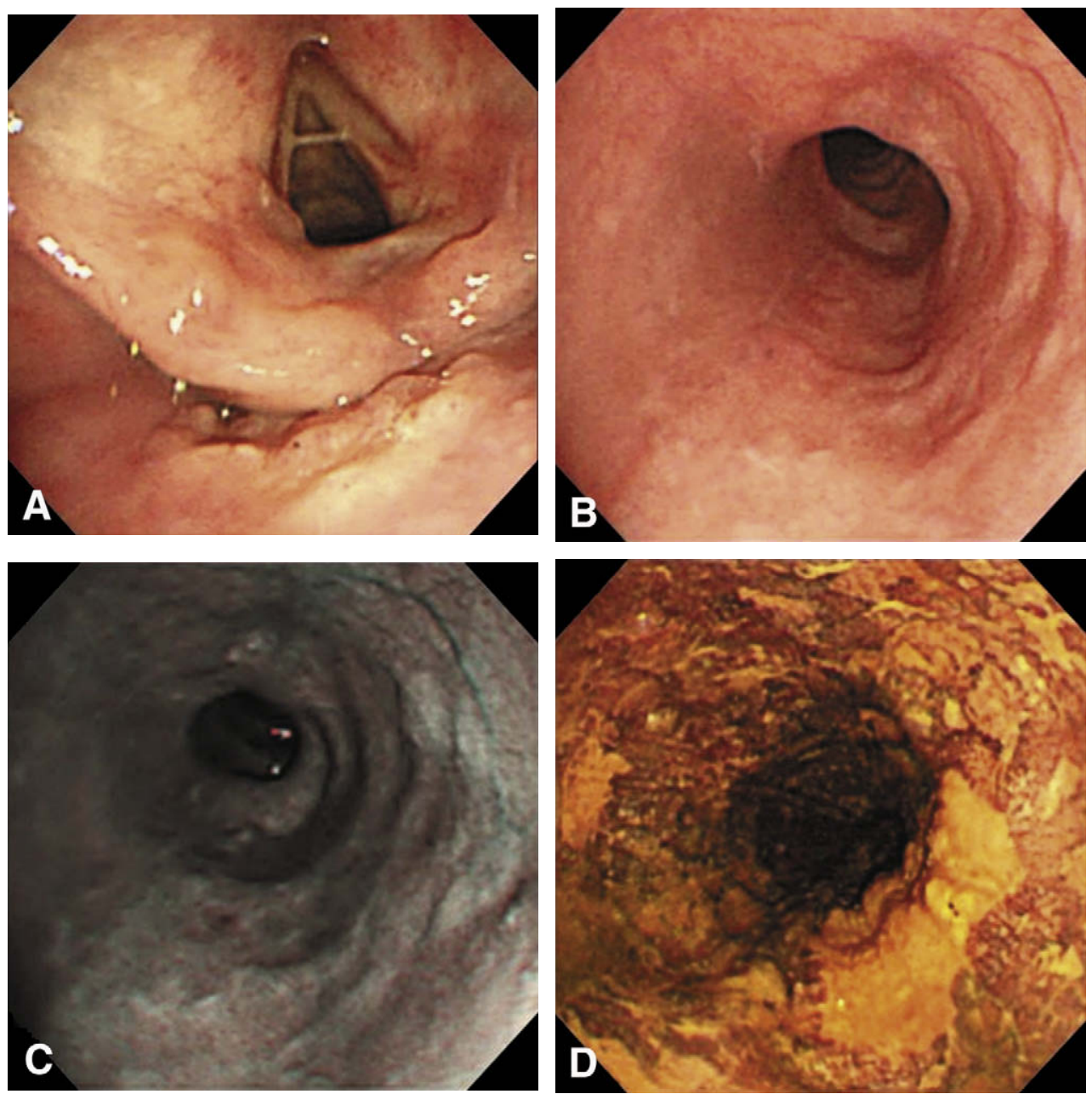

Figure 1. A false-negative lesion on standard endoscopy, which was detected on both NBI and Lugol chromoendoscopy. A, A small cancerous lesion was seen at the posterior wall of hypopharynx. B and C, During inspection with NBI, a dark-brownish area was noted at 3 o'clock (C), which was barely identified by standard endoscopy $(\mathbf{B})$. D, Lugol chromoendoscopy showed a well-demarcated LVL with central malignant change.

methods. Of 2 lesions missed with NBI, one appeared as a diffuse, brownish change, without definable margins (Fig. 2), and the other was obscured by blood oozing from a hypopharyngeal cancer. Of the lesions missed during chromoendoscopy, one appeared as an irregularly shaped, undyed area (Fig. 3), and the other was a small $(<5 \mathrm{~mm})$, undyed area (Fig. 4). Both could not be identified without NBI, because the background had multiple unstained areas (Video 1, available online at www.giejournal. org). The overall rate of concordance between these modalities was $75.9 \%$. Based on 1000 replicate samples from the study population, the estimated miss rate was 1.2\% (95\% CI, $0.1 \%-4.6 \%)$ after we integrated the information generated from the 3 endoscopic approaches.

\section{DISCUSSION}

Endoscopy plays a pivotal role in screening the aerodigestive tract for early tumors. The incidence of oropharyn- geal and esophageal cancer has increased in geographical areas where use of cigarette, alcohol, and betel nuts is prevalent. ${ }^{31-33}$ Esophageal cancer is pervasive in patients with head and neck cancer, with a prevalence of $9.1 \%$ to 22.6\% ${ }^{34-40}$ Multiple LVLs at baseline are associated with the highest risk (odds ratio range 3.3-21.4). ${ }^{19,20}$ H pylori infection (50\%) was prevalent among our patients, whose digestive tracts are difficult to examine. This situation was similar to observations in the general population in Taiwan $^{41}$ and supported findings from a recent pooled analysis that showed no association between $H$ pylori infection and the risk of esophageal squamous-cell carcinoma. ${ }^{42}$ However, the prevalence of peptic ulcer disease and erosive esophagitis was higher than expected.

The appearances of superficial esophageal tumors range from focal reddish areas to nodularity, as seen under standard endoscopy. ${ }^{43}$ We suggested that ultrathin endoscopy could be used in conjunction with NBI and Lugol chromoendoscopy to improve detection, as occurred 

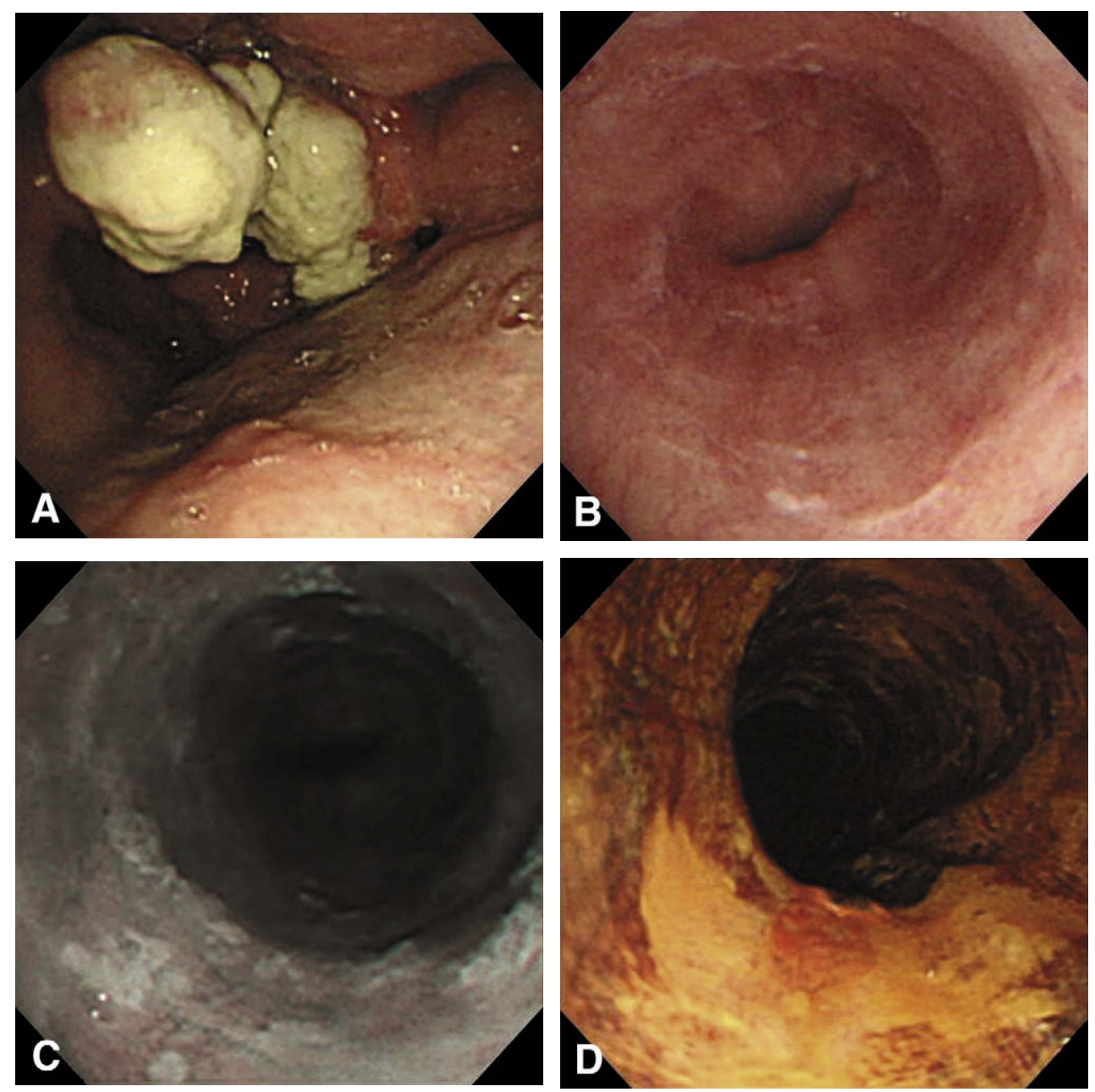

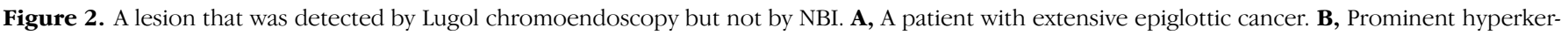

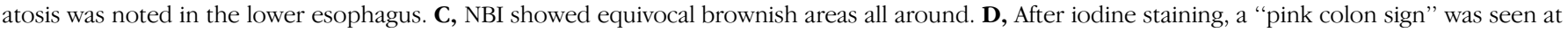
the cancer focus in a well-demarcated LVL.

when standard endoscopy was performed with Lugol staining; the detection rate increased from $62 \%$ for endoscopy alone to $91 \%$ to $100 \%$ for endoscopy combined with a Lugol study. ${ }^{13}$ In several preliminary reports, investigators compared detection with NBI versus Lugol chromoendoscopy in high-risk populations. ${ }^{44-47}$ Chiu et al ${ }^{44}$ reported a detection rate of $92.3 \%$ with both modalities, but the specificity of Lugol chromoendoscopy was lower than that of NBI (72.2\% vs 91.7\%). Both Lee et $\mathrm{al}^{45}$ and Ponchon et $\mathrm{al}^{46}$ found perfect concordance in the detection rate of $100 \%$ for NBI and Lugol chromoendoscopy. Nonetheless, Ponchon et $\mathrm{al}^{46}$ noted that the $75 \%$ specificity of NBI was low, which might have been related to a false detection of nonspecific inflammation.

The present study was not intended to compare the detection rate of NBI with that of Lugol chromoendoscopy, because both techniques reveal lesions equally well, ${ }^{44-46}$ and a large sample would have been needed to identify a minimal statistical difference. In addition, the Lugol stain- ing technique is unsurpassed for delineating the margins of cancerous foci, thereby facilitating biopsy or mucosectomy. ${ }^{18,19,48}$ Although the overall concordance between these techniques in our study was satisfactory (75.9\%), their discordance has technical implications. First, NBI is especially worthwhile for screening patients with multiple Lugol unstained areas. Katada et $\mathrm{al}^{19}$ found that only $17.3 \%$ of 434 biopsy specimens from LVLs indicated cancerous lesions. We observed that NBI could overcome the low specificity (40\%-95\%) and low PPV (13\%-52\%) associated with Lugol chromoendoscopy ${ }^{13}$ and thereby improve the diagnostic rate of targeted biopsy. Second, inflammation or hemorrhage may obscure observation with NBI, during which nonspecific absorbance of narrow-band light may hide lesions in endoscopic fields. Thus, both detection modalities offer complementary information that can minimize the risk of obtaining false-negative results.

The value of endoscopy in screening for second primary neoplasms has been debated. Findings are few, and 

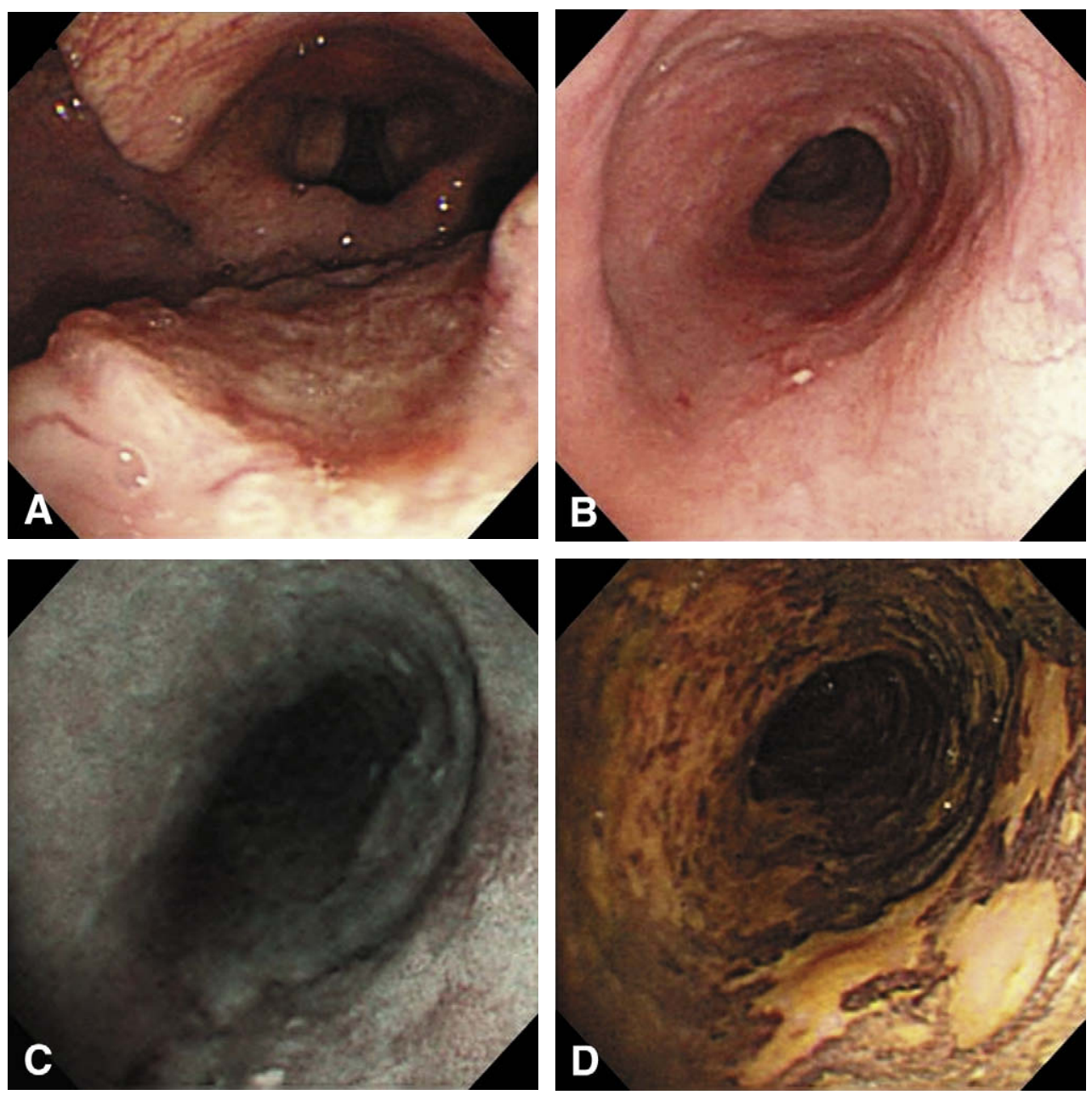

Figure 3. A lesion (identified as doubtful by Lugol chromoendoscopy) was confirmed by NBI. A to C, In a patient with hypopharyngeal cancer (A), NBI detected brownish areas at 3-6 o'clock (C), which appeared slightly reddish on standard endoscopy (B). D, Multiple irregular-shaped multiform undyed areas were noted after staining with Lugol's solution, which made biopsy difficult without localization by NBI.

convincing data about the effect of endoscopic screening on survival rates are lacking. Marchetta et $\mathrm{al}^{49}$ reported 3year and 5 -year survival rates of $21 \%$ and $9 \%$, respectively, in patients with multiple primary cancers of the head and neck. However, improvements in high-resolution magnifying endoscopy have increased the detection of minute neoplasms and have facilitated curative treatment with mucosectomy or submucosal dissection. ${ }^{43}$ Minimally invasive treatment for early stage lesions has contributed to a cause-specific 3 -year survival rate of $100 \%$ after mucosectomy ${ }^{19}$ and a multidisciplinary approach for treating synchronous neoplasms has lengthened the 5 -year survival to $34.5 \% .^{8,50-53}$

In our study, the sequential approach enabled us to detect and pathologically diagnose synchronous hypopharyngeal and esophageal invasive cancers in 6 patients. In all, treatment plans were changed after simultaneous esophageal cancers were detected. In addition, patients with mucosal dysplastic lesions were candidates for close endoscopic surveillance after their hypopharyngeal cancers were treated. Barium esophagography and magnetic resonance imaging are the traditional alternatives to endoscopy in patients with limited oral access. ${ }^{37}$ However, in our series, none of the superficial neoplasms could be detected with these studies.

The current study raised some concerns. First, although the data confirmed the accuracy of the sequential approach for detecting esophageal tumors, interobserver reliability was not determined. However, interpretations based on endoscopy with NBI are considerably less variable than those based on standard endoscopy alone. ${ }^{26,27}$ Moreover, the reliability of interpretation based on Lugol chromoendoscopy can be improved with information derived from previous NBI endoscopy. Second, although transnasal ultrathin endoscopy might increase patient tolerance for long procedures, the achievement of higher resolution and a brighter image than before is undoubtedly important. Further innovation, such as the use of 

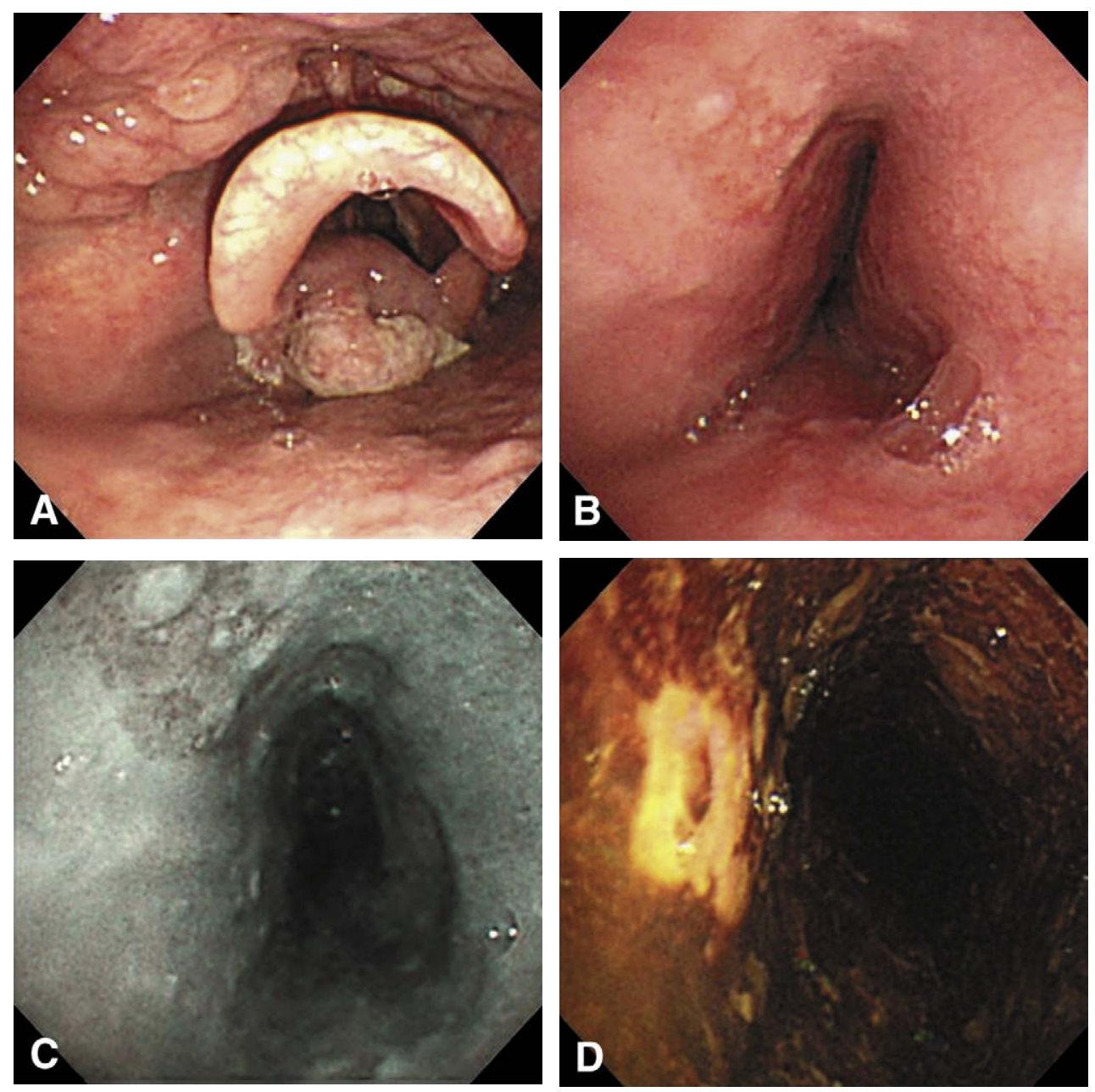

Figure 4. A lesion (identified as doubtful by Lugol chromoendoscopy) was confirmed by NBI. A to $\mathbf{C}$, In a patient with hypopharyngeal cancer (A), NBI detected the cancerous lesion as dark-brownish change at 11 o'clock $(\mathbf{C})$, which was missed by standard endoscopy (B). D, Lugol chromoendoscopy found many small LVLs in addition to a tiny undyed area $(<5 \mathrm{~mm})$ detected by NBI but easily overlooked without the use of NBI.

high-resolution charge-coupled devices, strong-power light sources, and enhanced integration of the imaging system (electronic circuits module, optics, etc), can be expected to improve image quality. Also, the sequential approach described in our study was intuitive. It can be used with instruments with large-diameter lenses and high image resolution to evaluate changes in intrapapillary capillary loops. ${ }^{43}$ Therefore, further research is warranted to compare combinations of other endoscopic techniques (eg, magnifying endoscopy, autofluorescence endoscopy, laser endomicroscopy, and other staining techniques) with the present one. ${ }^{54,55}$ Furthermore, longitudinal follow-up of treated patients is necessary to determine the effect of this approach on survival.

In conclusion, our data confirmed the feasibility of using a transnasal approach that combined standard endoscopy, NBI, and Lugol chromoendoscopy to detect tumors in a single session. This technique substantially increases the detection rate of synchronous or metachronous lesions and can be used to screen high-risk patients whose condition limits transoral passage.

\section{ACKNOWLEDGMENT}

The study benefited from statistical analysis performed at the Centre of Biostatistics Consultation, College of Public Health, National Taiwan University, Taipei, Taiwan.

\section{REFERENCES}

1. Hamilton SR, Aaltonen LA, editors. World Health Organization classification of tumours. Pathology and genetics of tumours of the digestive system. Lyon (France): IARC Press; 2000.

2. Gupta PC, Warnakulasuriya S. Global epidemiology of areca nut usage. Addict Biol 2002;7:77-83.

3. Mariette C, Piessen G, Triboulet JP. Therapeutic strategies in oesophageal carcinoma: role of surgery and other modalities. Lancet Oncol 2007;8:545-53. 
4. Kleinberg L, Forastiere AA. Chemoradiation in the management of esophageal cancer. J Clin Oncol 2007;25:4110-7.

5. Haughey BH, Gates GA, Arfken $\mathrm{CL}$, et al. Meta-analysis of second malignant tumors in head and neck cancer: the case for an endoscopic screening protocol. Ann Otol Rhinol Laryngol 1992;101: 105-12.

6. Schwartz LH, Ozsahin M, Zhang GN, et al. Synchronous and metachronous head and neck carcinomas. Cancer 1994;74:1933-8.

7. Nakamura K, Shioyama $Y$, Kawashima $M$, et al. Multi-institutional analysis of early squamous cell carcinoma of the hypopharynx treated with radical radiotherapy. Int J Radiat Oncol Biol Phys 2006;65: 1045-50.

8. Natsugoe $\mathrm{S}$, Matsumoto $\mathrm{M}$, Okumura $\mathrm{H}$, et al. Multiple primary carcinomas with esophageal squamous cell cancer: clinicopathologic outcome. World J Surg 2005;29:46-9.

9. Muto $M$, Takahashi $M$, Ohtsu $A$, et al. Risk of multiple squamous cell carcinomas both in the esophagus and the head and neck region. Carcinogenesis 2005;26:1008-12.

10. Shiozaki $H$, Tahara $H$, Kobayashi $K$, et al. Endoscopic screening of early esophageal cancer with the Lugol dye method in patients with head and neck cancers. Cancer 1990;66:2068-71.

11. Yokoyama A, Ohmori T, Makuuchi $H$, et al. Successful screening for early esophageal cancer in alcoholics using endoscopy and mucosa iodine staining. Cancer 1995;76:928-34.

12. Meyer V, Burtin P, Bour B, et al. Endoscopic detection of early esophageal cancer in a high-risk population: does Lugol staining improve videoendoscopy? Gastrointest Endosc 1997;45:480-4.

13. Dawsey $S M$, Fleischer $D E$, Wang $G Q$, et al. Mucosal iodine staining improves endoscopic visualization of squamous dysplasia and squamous cell carcinoma of the esophagus in Linxian, China. Cancer 1998;83:220-31.

14. Freitag CP, Barros SG, Kruel CD, et al. Esophageal dysplasias are detected by endoscopy with Lugol in patients at risk for squamous cell carcinoma in southern Brazil. Dis Esophagus 1999;12: 191-5.

15. Tincani AJ, Brandalise N, Altemani A, et al. Diagnosis of superficial esophageal cancer and dysplasia using endoscopic screening with a $2 \%$ Lugol dye solution in patients with head and neck cancer. Head Neck 2000;22:170-4.

16. Hashimoto $\mathrm{CL}$, Iriya $\mathrm{K}$, Baba ER, et al. Lugol's dye spray chromoendoscopy establishes early diagnosis of esophageal cancer in patients with primary head and neck cancer. Am J Gastroenterol 2005;100: 275-82.

17. Wong Kee Song LM, Adler DG, Chand B, et al. Chromoendoscopy. Gastrointest Endosc 2007;66:639-49.

18. Yamamoto $\mathrm{H}$. Technology insight: endoscopic submucosal dissection of gastrointestinal neoplasms. Nat Clin Pract Gastroenterol Hepatol 2007;4:511-20.

19. Katada C, Muto M, Manabe T, et al. Local recurrence of squamous-cell carcinoma of the esophagus after EMR. Gastrointest Endosc 2005;61: 219-25.

20. Muto M, Hironaka S, Nakane M, et al. Association of multiple Lugolvoiding lesions with synchronous and metachronous esophageal squamous cell carcinoma in patients with head and neck cancer. Gastrointest Endosc 2002;56:517-21.

21. Kumagai $Y$, Toi $M$, Inoue $H$. Dynamism of tumour vasculature in the early phase of cancer progression: outcomes from oesophageal cancer research. Lancet Oncol 2002;3:604-10.

22. Gono K, Obi T, Yamaguchi M, et al. Appearance of enhanced tissue features in narrow-band endoscopic imaging. J Biomed Opt 2004;9: 568-77.

23. Muto $M$, Nakane $M$, Katada $C$, et al. Squamous cell carcinoma in situ at oropharyngeal and hypopharyngeal mucosal sites. Cancer 2004;101: 1375-81.

24. Yoshida $T$, Inoue $H$, Usui $S$, et al. Narrow-band imaging system with magnifying endoscopy for superficial esophageal lesions. Gastrointest Endosc 2004;59:288-95.
25. Muto M, Katada C, Sano Y, et al. Narrow band imaging: a new diagnostic approach to visualize angiogenesis in superficial neoplasia. Clin Gastroenterol Hepatol 2005;3(Suppl 1):S16-20.

26. Lee YC, Lin JT, Chiu HM, et al. Intraobserver and interobserver consistency for grading esophagitis with narrow-band imaging. Gastrointest Endosc 2007;66:230-6.

27. Sharma $P$, Wani $S$, Bansal A, et al. A feasibility trial of narrow band imaging endoscopy in patients with gastroesophageal reflux disease. Gastroenterology 2007;133:454-64.

28. Dixon MF. Gastrointestinal epithelial neoplasia: Vienna revisited. Gut 2002;51:130-1.

29. Gardner JD. How do I interpret a positive diagnostic test? Gastrointest Endosc 2007;66:891-3.

30. Malone FD. Sequential pathways of testing after first-trimester screening for trisomy 21. Obstet Gynecol 2005;105:438.

31. Age-specific incidence rates of major cancers in Taiwan, Taiwan Cancer Registry, Department of Health, Executive Yuan: Taiwan; 2002 Available at: http://crs.cph.ntu.edu.tw/. Assessed January 7, 2008.

32. Yen AM, Chen SC, Chen TH. Dose-response relationships of oral habits associated with the risk of oral pre-malignant lesions among men who chew betel quid. Oral Oncol 2007;43:634-8.

33. Shiu MN, Chen TH, Chang SH, et al. Risk factors for leukoplakia and malignant transformation to oral carcinoma: a leukoplakia cohort in Taiwan. Br J Cancer 2000;82:1871-4.

34. Jones AS, Morar P, Phillips DE, et al. Second primary tumors in patients with head and neck squamous cell carcinoma. Cancer 1995;75: 1343-53.

35. Takiyama W, Moriwaki S, Mandai K, et al. Relationship of esophageal dysplasia to associated head and neck cancer in patients with esophageal carcinoma. Jpn J Clin Oncol 1996;26:12-7.

36. Natsugoe S, Uchino Y, Kijima F, et al. Synchronous and metachronous carcinomas of the esophagus and head and neck. Dis Esophagus 1997;10:134-8.

37. Kohmura T, Hasegawa $Y$, Matsuura $H$, et al. Clinical analysis of multiple primary malignancies of the hypopharynx and esophagus. Am J Otolaryngol 2001;22:107-10.

38. Petit T, Georges C, Jung GM, et al. Systematic esophageal endoscopy screening in patients previously treated for head and neck squamouscell carcinoma. Ann Oncol 2001;12:643-6.

39. Raghavan U, Quraishi S, Bradley PJ. Multiple primary tumors in patients diagnosed with hypopharyngeal cancer. Otolaryngol Head Neck Surg 2003;128:419-25.

40. Hujala K, Sipilä J, Grenman R. Panendoscopy and synchronous second primary tumors in head and neck cancer patients. Eur Arch Otorhinolaryngol 2005;262:17-20.

41. Lee YC, Wu HM, Chen TH, et al. A community-based study of Helicobacter pylori therapy using the strategy of test, treat, retest, and retreat initial treatment failures. Helicobacter 2006;11: 418-24.

42. Rokkas T, Pistiolas D, Sechopoulos P, et al. Relationship between Helicobacter pylori infection and esophageal neoplasia: a meta-analysis. Clin Gastroenterol Hepatol 2007;5:1413-7.

43. Cohen J, editor. Comprehensive atlas of high resolution endoscopy and narrowband imaging. Magnifying endoscopic diagnosis of tissue atypia and cancer invasion depth in the area of pharyngoesophageal squamous epithelium by $\mathrm{NBI}$ enhanced magnification image: IPCL pattern classification. Malden: Blackwell Publishing; 2007.

44. Chiu PW, Cheung FK, Tsang RK, et al. Narrow band imaging (NBI) against conventional Lugol chromoendoscopy for detection of superficial esophageal neoplasia in high risk patients: a prospective comparative study [abstract]. Gastrointest Endosc 2007;65:AB332.

45. Lee IL, Wu CS, Hwang TZ, et al. A prospective comparative study of narrow-band imaging, Lugol's chromoendoscopy and conventional endoscopy for the detection of esophageal cancer in patients 
with head and neck cancer [abstract]. Gastroenterology 2007;132 A168.

46. Ponchon T, Lapalus $M$, Saurin J, et al. Could narrow band imaging (NBI) replace Lugol staining for the detection of esophageal squamous cell carcinoma? [abstract] Gastrointest Endosc 2007;65: AB343.

47. Ide E, Matuguma S, Moura EH, et al. Endoscopic observation with the NBI system was useful for detecting obscure squamous cell carcinoma in esophageal mucosa? Preliminary results [abstract]. Gastrointest Endosc 2007;65:AB353.

48. Connor MJ, Sharma P. Chromoendoscopy and magnification endoscopy for diagnosing esophageal cancer and dysplasia. Thorac Surg Clin 2004;14:87-94.

49. Marchetta FC, Sako K, Camp F. Multiple malignancies in patients with head and neck cancer. Am J Surg 1965;110:537-41.

50. Tachimori $\mathrm{Y}$, Watanabe $\mathrm{H}$, Kato $\mathrm{H}$, et al. Treatment for synchronous and metachronous carcinomas of the head and neck and esophagus. J Surg Oncol 1990;45:43-5.

51. Yoshino K, Endo M, Nara S, et al. Surgery for synchronous double cancer in the hypopharynx and thoracic esophagus. Hepatogastroenterology 1995;42:275-8.

52. Wind $P$, Roullet $M H$, Douard $R$, et al. Experience in the treatment of synchronous and metachronous carcinoma of the oesophagus and the head and neck. J Surg Oncol 2000;73:138-42.

53. Suzuki S, Nishimaki T, Suzuki T, et al. Outcomes of simultaneous resection of synchronous esophageal and extraesophageal carcinomas. J Am Coll Surg 2002;195:23-9.
54. Curvers WL, Singh R, Wong Kee Song LM, et al. Endoscopic tri-moda imaging for detection of early neoplasia in Barrett's oesophagus; a multi-centre feasibility study using high-resolution endoscopy, autofluorescence imaging and narrow band imaging incorporated in one endoscopy system. Gut 2008;57:167-72.

55. Pech $\mathrm{O}$, Rabenstein $\mathrm{T}$, Manner $\mathrm{H}$, et al. Confocal laser endomicroscopy for in vivo diagnosis of early squamous cell carcinoma in the esophagus. Clin Gastroenterol Hepatol 2008;6:89-94.

Received January 22, 2008. Accepted May 5, 2008.

Current affiliations: Departments of Internal Medicine (Y.-C.L., C.-C.C., H.-M.C., M.-S.W., J.-T.L., H.-P.W.), Otolaryngology (C.-P.W., J.-Y.K., P.-J.L., T.-L.Y.), Pathology (H.-Y.H.), National Taiwan University Hospital, Division of Biostatistics (Y.-C.L., T.H.-H.C.), Graduate Institute of Epidemiology, College of Public Health, Institute of Biomedical Engineering (C.-P.W., T.-L.Y.), College of Medicine and College of Engineering, National Taiwan University, Taipei, Taiwan.

Presented at Digestive Disease Week Conference, May 17-22, 2008, San Diego, California (Gastrointest Endosc 2008;67:AB127).

Reprint requests: Hsiu-Po Wang, MD, Department of Internal Medicine, National Taiwan University Hospital, 7, Chung-Shan South Rd, Taipei 100 Taiwan.

If you want to chat with an author of this article, you may contact him at wanghp@ntu.edu.tw.

Access to Gastrointestinal Endoscopy Online is reserved for all subscribers!

Full-text access to Gastrointestinal Endoscopy Online is available for all subscribers. ASGE MEMBER SUBSCRIBERS: To activate your individual online subscription, please visit http://www.asge.org and follow the instructions. NONMEMBER SUBSCRIBERS: To activate your individual online subscription, please visit http://www. giejournal.org and follow the prompts to activate your online access. To activate your account, you will need your subscriber account/membership number, which you can find on your mailing label (note: the number of digits in your subscriber account number varies from 6 to 10 digits). See the example below in which the subscriber account number has been circled:

Sample mailing label

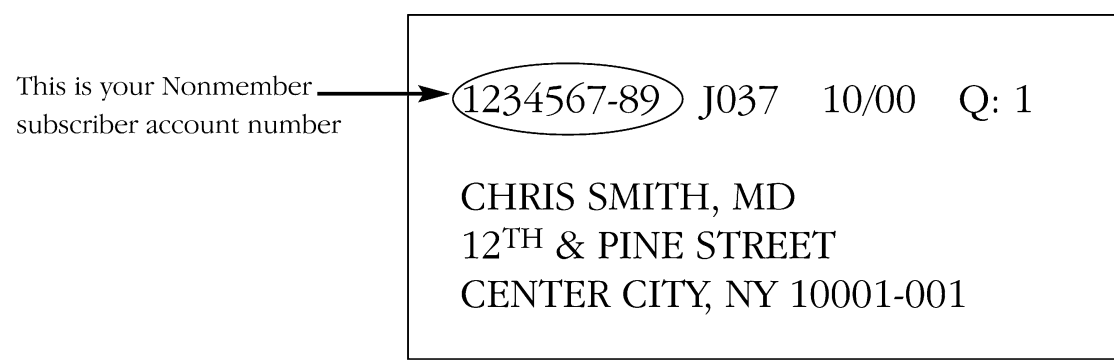

Personal subscriptions to Gastrointestinal Endoscopy Online are for individual use only and may not be transferred. Use of Gastrointestinal Endoscopy

Online is subject to agreement to the terms and conditions as indicated online. 